7) Chu, C. and L. C. Tsang: Ind. Eng. Chem., Process Des. Dev., 10, 47 (1971).

8) Deckwer, W. and E. A. Mählmann: Chem. Eng. J., 11, 19 (1976).

9) Danckwerts, P. V.: Chem. Eng. Sci., 2, 1 (1953).

10) Fan, L. T. and Y. K. Ahn: Ind. Eng. Chem., Process Des. Dev., 1, 190 (1962).

11) Fan, L. T. and R. C. Bailie: Chem. Eng. Sci., 13, 63 (1960).

12) Gunn, D. J.: Trans. Inst. Chem. Engrs., 46, CE153 (1968).

13) idem: ibid., 47, T351 (1969).

14) Hofmann, H. and H. J. Astheimer: Chem. Eng. Sci., 18, 643 (1963).

15) Lannus, A. and L.S. Kershenbaum: AIChE J., 16, 329 (1970).

16) Liu, S. L. and N. R. Amundson: Ind. Eng. Chem., Fundam., 2, 183 (1963).

17) Lorenz, M. G.: Ind. Eng. Chem., Process Des. Dev., 2, 88 (1963).

18) Mears, D. E.: Chem. Eng. Sci., 26, 1361 (1971).

19) Olbrich, W. E., J. B. Agnew, and O. E. Potter: Trans.
Inst. Chem. Engrs., 44, T207 (1966).

20) Pearson, J. R. A.: Chem. Eng. Sci., 10, 281 (1959).

21) Schmeal, W. R. and N. R. Amundson: AIChE J., 12, 1202 (1966).

22) Shah, Y. T. and J.A. Paraskos: Chem. Eng Sci., 30, 465 (1975).

23) Standart, G.: ibid., 23, 645 (1968).

24) Strand, C.P., R.B. Olney, and G.H. Ackerman: AIChE J., 8, 252 (1962).

25) Tichacek, L. J.: ibid., 9, 394 (1963).

26) Van Cauwenberghe, A. R.: Chem. Eng. Sci., 21, 203 (1966).

27) Van der Laan, E. T.: ibid., 7, 187 (1958).

28) Villermaux, J. and W. P. M. Van Swaaij: ibid., 24, 1097 (1969).

29) Wehner, J. F. and R. H. Wilhelm: ibid., 6, 89 (1956).

30) Wen, C. Y. and L. T. Fan: "Models for Flow Systems and Chemical Reactors", Marcel Dekker, Inc., New York (1975).

31) Wissler, E. H.: Chem. Eng. Sci., 24, 527 (1969).

\title{
THE EFFECT OF STABILIZER ON COALESCENCE OF DISPERSED DROPS IN SUSPENSION POLYMERIZATION OF STYRENE
}

\author{
Mikio KONNO, Kunio ARAI and Shozaburo SAITO \\ Department of Chemical Engineering, \\ Tohoku University, Sendai 980
}

\begin{abstract}
Suspension polymerization of styrene was conducted to study the effect of polyvinyl alcohol, added as a stabilizer to the continuous phase, on dispersed drop size distribution. Transient drop size distributions were measured under several experimental conditions with dispersedphase volume fractions ranging from 0.1 to 0.5 and stabilizer concentrations from 0.3 to $10 \mathrm{~g} / \mathrm{l}$. The experimental results show that at the early stage of the reaction, where the dispersed phase viscosity is lower than about $\mathbf{5 0} \mathrm{cp}$, drop size does not depend upon stabilizer concentration. Above this viscosity, stabilizer concentration influences on drop size. Whenever drop agglomeration occurs, drop size distribution reveals a bimodal form in which the lower drop size mode in the distribution maintains a constant drop diameter while the higher drop size mode moves toward a larger drop size. The experimental results may be accounted for by the hypothesis that the coalescence of dispersed drops above the maximum stable drop size for breakup is not effectively prevented by the stabilizer.
\end{abstract}

\section{Introduction}

The well-known process of suspension polymerization usually utilizes an agitated liquid-liquid dispersion. In general, when an immiscible liquid is agitated in water, dynamic equilibrium is attained between coalescence and breakup, and a steady dis-

Received August 5, 1981. Correspondence concerning this article should be addressed to $S$. Saito. persion is formed. An increase of dispersed phase viscosity, with an increase in conversion of monomer to polymer within each drop, results in variations in breakup and coalescence frequencies, so that the size distribution of dispersed drops shifts towards the establishment of a new dynamic equilibrium. Above a certain level of conversion, the dispersed drops agglomerate remarkably and, in some cases, an entirely stable dispersion cannot be maintained. 


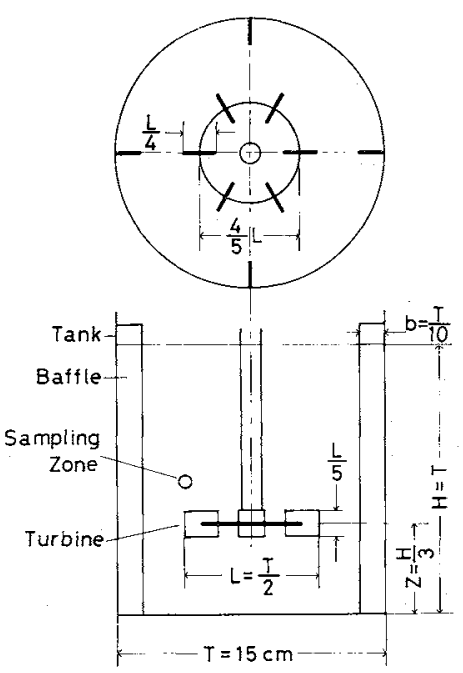

Fig. 1 Schematic diagram of a stirred-tank reactor

Stabilizers such as polyvinyl alcohol (PVA), therefore, are usually added to the continuous phase to depress the coalescence frequency. It is of considerable importance to elucidate this depression effect of a stabilizer in controlling the size distribution of polymer particles formed in suspension polymerization. Hopff et al..$^{2,31}$ and Winslow et al. ${ }^{7)}$ investigated the relation between the average diameter of polymer particles and the operational variables, including stabilizer concentration, and derived a correlation among them by means of dimensional analysis. However, since the depression effect of a stabilizer undergoes remarkable changes during polymerization, it is difficult to provide a substantial account without a knowledge of transient drop size distributions. Thus Takao et al. ${ }^{6)}$ and Mizoguchi et al..$^{5)}$, who measured transient drop size distributions in suspension polymerization of styrene with use of PVA as a stabilizer, reported that bimodal drop size distribution appears under certain experimental conditions. Although their investigations provide useful information on the factors controlling polymer particle size, these authors have not given a detailed discussion of the origin of the bimodal distributions.

In this work, in order to elucidate the mechanism of the depression effect of the stabilizer on coalescence frequency and to explain the variation in drop size distribution during polymerization, transient drop size distributions were examined during suspension polymerization of styrene at different PVA concentrations and dispersed-phase volume fractions.

\section{Experiment}

Figure 1 shows a schematic diagram of a stirredtank reactor, a cylindrical glass vessel equipped with four equally-spaced baffles and a six-bladed disk turbine impeller, all of stainless steel.
Table 1 Physical properties of two-phase liquids at initial stage of polymerization $\left(70^{\circ} \mathrm{C}\right)$

\begin{tabular}{ccc} 
Continuous phase $=$ & $\begin{array}{l}\text { distilled water }+ \text { stabilizer (PVA with } \\
\text { polymerization degree of about 2000) }\end{array}$ \\
Dispersed phase & $\begin{array}{l}\text { styrene }+o \text {-xylene }+ \text { initiator (azobis- } \\
\text { isobutyronitrile) } \\
\text { weight fraction of } o \text {-xylene }=0.05 \\
\text { concentration of initiator }=0.05 \mathrm{~mol} / l\end{array}$ \\
$\begin{array}{c}\text { Dispersed-phase viscosity }=0.44 \mathrm{cp} \\
\text { PVA concentration } \\
\text { in continuous }\end{array}$ & $\begin{array}{c}\text { Continuous-phase } \\
\text { phase }[\mathrm{g} / l]\end{array}$ & $\begin{array}{c}\text { Interfacial } \\
\text { tension }[\mathrm{dyne} / \mathrm{cm}]\end{array}$ \\
\hline 0.3 & & \\
\hline 0.5 & 0.40 & 20 \\
1.0 & 0.41 & 19.5 \\
10 & 0.43 & 18.5 \\
& 0.82 & 15
\end{tabular}

The dispersed and continuous phase liquids were prepared as shown in Table 1. Conversion of styrene monomer to polymer was determined by gas chromatography with the use of $o$-xylene as an internal standard. Physical properties of the liquids are also summarized in Table 1.

In a laboratory-scale mixing vessel, gas will be easily introduced from the free surface into the agitated liquid, since the Froude number in a smaller mixing vessel has a larger value under the condition of constant power consumption per unit volume. In a preliminary experiment, it was found that dispersed drop size is greatly affected by the introduction of gas (described in detail in Appendix). To avoid the complicating effect of the introduction of gas, the impeller was located at a height of $1 / 3$ the vessel diameter from the bottom and impeller speed was set at $240 \mathrm{rpm}$.

The reactor was filled with the reaction mixture to a height equal to the vessel diameter, and suspension polymerization was carried out at a constant temperature of $70^{\circ} \mathrm{C}$, a constant impeller speed of $240 \mathrm{rpm}$, dispersed-phase volume fractions of 0.1 , 0.2 and 0.5 , and stabilizer concentrations of $0.3,0.5$, 1.0 and $10 \mathrm{~g} / \mathrm{l}$.

At appropriate intervals about $1 \mathrm{~m} l$ of reaction mixture was drawn off with a glass pipet from the sampling position shown in Fig. 1 and transferred to a laboratory dish containing $30 \mathrm{~g} / \mathrm{l}$ aqueous solution of PVA to prevent the sampled drops from coalescing. The sampled drops were photographed. From the projection of the negative onto a frosted glass screen, individual diameters of more than three hundred drops were measured and the drop size distribution was obtained.

The sampled drops were also subjected to determination by gas chromatography of monomer conversion in the dispersed phase. Figure 2 shows a time-conversion curve for each run. Vertical lines in this figure represent the scatter of data. The same figure also shows the change in dispersed-phase vis- 
cosity during the reaction. The viscosity was calculated from the correlation equation reported by Hui and $\mathrm{Hamielec}^{4)}$, with the use of the time-conversion curve and the degree of polymerization as calculated at the initial stage of the reaction.

\section{Results}

Figure 3 shows Sauter mean drop sizes in the course of the reaction for each dispersed-phase volume fraction at a constant stabilizer concentration of $S=$ $1.0 \mathrm{~g} / l$. The mean drop size for the dispersed-phase volume fraction of $\phi=0.5$ increases rapidly compared with the others, and a stable dispersion cannot be maintained around the middle stage of the reaction. For $\phi=0.1$ or 0.2 , mean drop size increases slowly at the early stage of the reaction and somewhat more rapidly after about 200 minutes when the drop viscosity is about $50 \mathrm{cp}$. The drops cease growing after about 400 minutes when the drop viscosity is about $3000 \mathrm{cp}$. Thus dispersed drops with viscosity higher than about $3000 \mathrm{cp}$ may be considered to behave like solid particles, which neither coalesce nor break up.

Figure 4 shows Sauter mean drop sizes in the course of the reaction for each stabilizer concentration at a constant dispersed-phase volume fraction of $\phi=0.1$. For a stabilizer concentration of $10 \mathrm{~g} / l$, the mean drop size remains unchanged during the reaction. On the other hand, for the lower stabilizer concentrations of $0.3,0.5$ and $1.0 \mathrm{~g} / l$ the mean drop sizes grow at the early and middle stage of the reaction. In spite of the difference in stabilizer concentration, the mean drop sizes have almost the same value at the early stage of the reaction, while they start to differ from each other according to stabilizer concentration after about 200 minutes when dispersed-phase viscosity is about $50 \mathrm{cp}$. Drop growth stops after about 400 minutes, as seen in Fig. 3. Thus, drop coalescence at the early stage of the reaction may be considered to be almost unaffected by stabilizer when its concentration is low enough for drops to grow.

Figures 5 to 7 represent transient drop size distributions during the reaction. It is observed in these figures that each drop size distribution reveals bimodal form as the reaction proceeds. The lower drop size mode in the distribution remains at an unchanged position on the horizontal axis, although the higher drop size mode moves toward a larger drop size. The time of the appearance of the bimodal form, however, depends upon the dispersed-phase volume fraction. For the large dispresed-phase volume fraction of $\phi=0.5$, the bimodal form is observed from the beginning of the reaction, while for the small value of $\phi=0.1$ it is seen from the middle stage of the reaction.

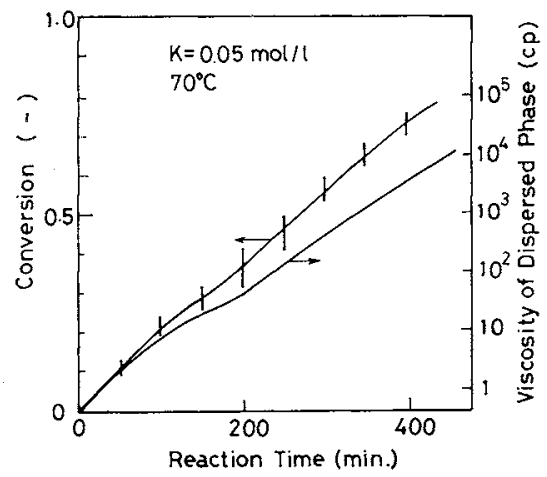

Fig. 2 Monomer-to-polymer conversion and dispersed-phase viscosity during reaction

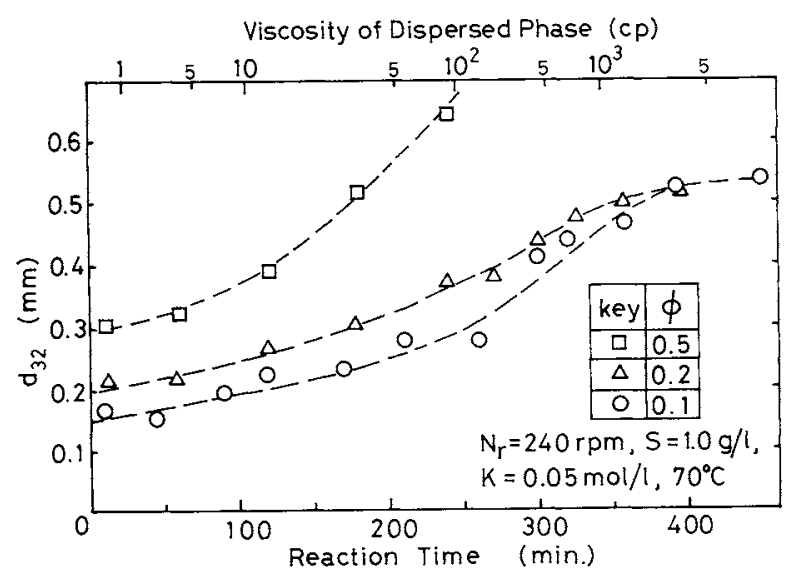

Fig. 3 Sauter mean drop sizes in the course of reaction for different dispersed-phase volume fractions

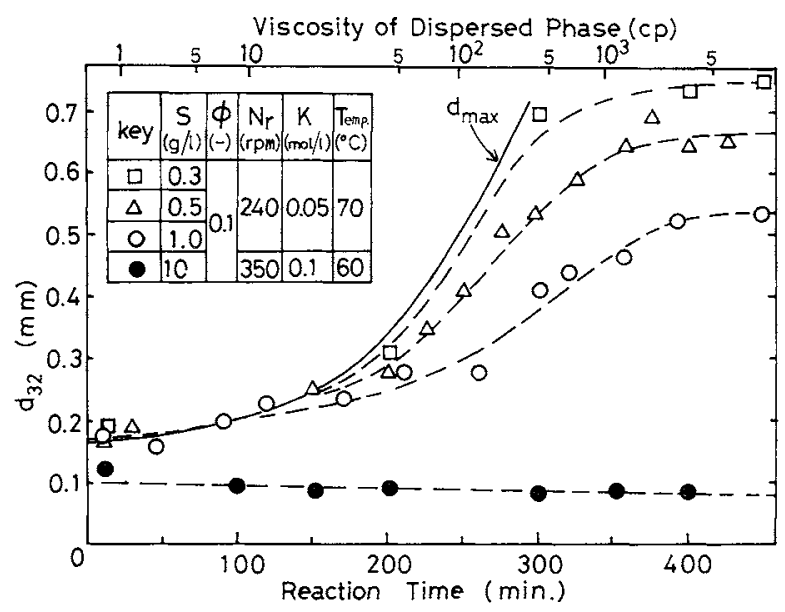

Fig. 4 Sauter mean drop sizes in the course of reaction for different stabilizer concentrations

Bimodal distributions are also observed in other experimental conditions, when agglomeration of dispersed drops occurs. This result is qualitatively consistent with that reported by Takao et $a l^{6}{ }^{6}$ and Mizoguchi et al. ${ }^{5}$.

\section{Discussion}

The calculated value of the maximum stable drop 


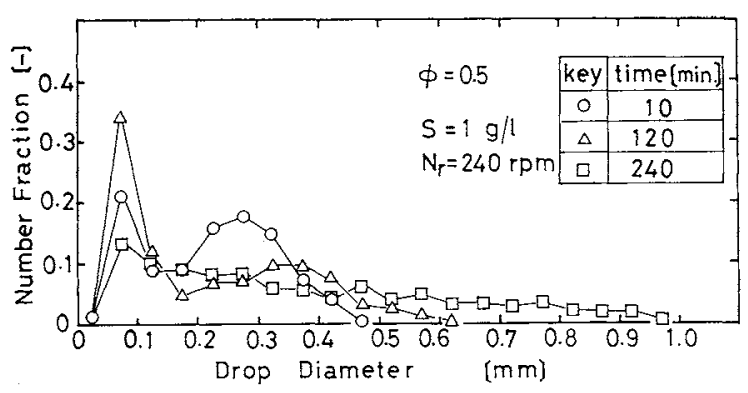

Fig. 5 Transient drop size distributions during reaction $(\phi=0.5, S=1 \mathrm{~g} / l)$

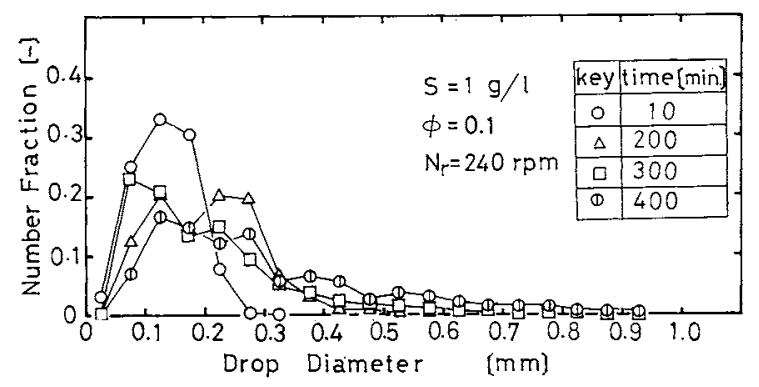

Fig. 6 Transient drop size distributions during reaction $(\phi=0.1, S=1 \mathrm{~g} / l)$

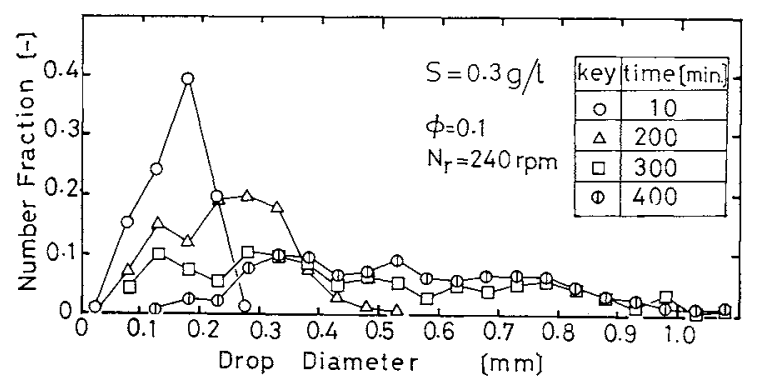

Fig. 7 Transient drop size distributions during reaction $(\phi=0.1, S=0.3 \mathrm{~g} / l)$

\section{Stabilized Drop}

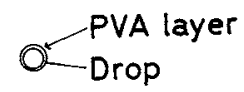

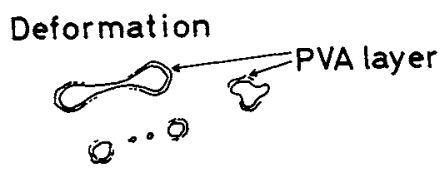

Fig. 8 Schematic representation of layer of stabilizer on drop surface

size, $d_{\max }$, is plotted against reaction time as a solid line in Fig. 4. The value of $d_{\max }$ varies with change in dispersed-phase viscosity and is estimated from the following correlation equation proposed in the previous paper ${ }^{1}$.

$$
\frac{\rho_{c} d_{\max }^{5 / 3} \bar{\varepsilon}^{2 / 3}}{\sigma}=0.015\left(1+9 \mu_{d} \bar{\varepsilon}^{1 / 3} d_{\max }^{1 / 3} / \sigma\right)
$$

where $\rho_{c}$ denotes continuous-phase density; $\sigma$, inter- facial tension; $\bar{\varepsilon}$, average energy dissipation rate per unit mass; and $\mu_{d}$, dispersed-phase viscosity. In Fig. 4, the mean drop sizes for the stabilizer concentrations of $0.3,0.5$ and $1.0 \mathrm{~g} / l$ are almost equal to $d_{\text {max }}$ at the early stage of the reaction. After about 200 minutes, when the mean drop sizes start to differ from each other, $d_{\max }$ increases remarkably owing to an increase in dispersed-phase viscosity and becomes larger than the mean drop sizes. The maximum stable drop size is defined as the largest diameter that drops may attain before breakup, and only drops of larger size than $d_{\max }$ break up. When a dispersed drop has a size close to $d_{\max }$, large deformation of the drop will frequently occur in turbulent flow, such as in the present agitated tank, and internal flow within the drop will be enhanced.

To account for the effect of stabilizer in Fig. 4 a hypothesis is introduced, as shown schematically in Fig. 8. The adsorbed stabilizer layer on the surface of a drop with dimensions close to $d_{\max }$ will be split due to the large deformation of the drop. Unless stabilizer concentration is extremely high, the split in the adsorbed layer will not be repaired immediately by the stabilizer, because of the low diffusion rate of a macromolecule stabilizer. In this case, the stabilizer will not effectively prevent drop coalescence. Then the mean drop size is independent of stabilizer concentration at the early stage of the reaction, as shown in Fig. 4. On the other hand, the split in the stabilizer layer on the surface of a drop smaller than $d_{\max }$ will not take place frequently and the coalescence frequency will depend upon stabilizer concentration. Accordingly, the mean drop sizes for each stabilizer concentration differ from each other after the middle stage of the reaction.

In addition, these considerations can also explain the origin of the bimodal distribution as follows. Small drops will hardly coalesce with each other since they are effectively protected by the stabilizer. Therefore, the lower drop size mode of the bimodal distribution maintains a constant diameter during the reaction. In contrast, a large drop will coalesce with a small one and more easily with a large one, so that the higher drop size mode is shifted toward a large drop size during the reaction. On the other hand, an increase of the portion of large drops with an increase in dispersed-phase volume fraction accelerates the coalescence frequency between large drops. This may result in the appearance of the bimodal distribution at the early stage of the reaction in Fig. 5 for $\phi=0.5$.

\section{Conclusions}

The following results are obtained from these experiments with the suspension polymerization of 
styrene.

1) Dispersed drop size does not depend upon stabilizer concentration at the early stage of the reaction, but is influenced by it after the middle stage of the reaction.

2) Bimodal drop size distribution appears during the reaction and the lower drop size mode in the distribution maintains a constant diameter.

The experimental results can be explained by considering that the stabilizer does not effectively prevent the coalescence of dispersed drops of a size larger than $d_{\max }$, owing to the considerable deformation of the dispersed drops.

\section{Appendix}

Figure A-1 shows Sauter mean drop sizes during a reaction in which gas is introduced through the free surface. This figure also shows Sauter mean drop size in a reactor which is equipped with a cover plate to prevent the introduction of gas. Since sampling this reaction mixture without introducing gas was impossible with this reactor, drop size distributions were not measured in the course of the reaction. Although the experimental conditions are identical except for the introduction of gas, the final drop size at about 600 minutes in the vessel with a free surface is much larger than that in the vessel without a free surface, as shown in Fig. A-1. Furthermore, it was found that polymer particles containing small bubbles were formed in the free-surface vessel. Therefore, it is obvious that the introduction of gas greatly affects the dispersed drop size.

\section{Nomenclature}

$d_{32} \quad=$ Sauter mean drop size

$d_{\text {max }} \quad=$ maximum stable drop size

$H \quad=$ height of free surface from bottom of a vessel

$K=$ initial concentration of initiator in dispersed phase

$N_{r} \quad=$ impeller speed

$S \quad=$ stabilizer concentration

$T \quad=$ vessel diameter

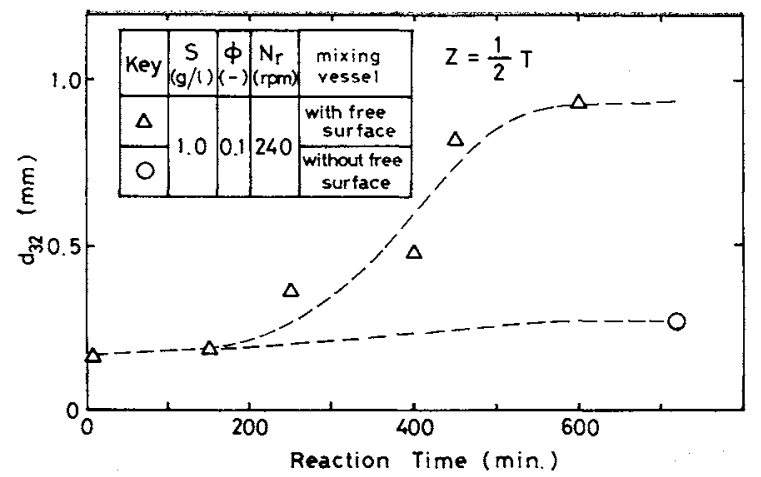

Fig. A-1 Effect of introduction of gas on dispersed drop size

$Z \quad=$ distance from center of impeller to bottom of vessel

$\bar{\varepsilon} \quad=$ average energy dissipation rate per unit mass

$\mu_{d} \quad=$ viscosity of dispersed phase

$\rho_{c} \quad=$ density of continuous phase

$\sigma \quad=$ interfacial tension

$\phi \quad=$ dispersed-phase volume fraction

\section{Literature Cited}

1) Arai, K., M. Konno, Y. Matsunaga and S. Saito: $J$. Chem. Eng. Japan., 10, 325 (1977).

2) Hopff, V. H., H. Lüssi, P. Gerspacher and E. Hammer: Chemie. Ing. Techn., 36, 1085 (1964).

3) Hopff, V. H. and E. Hammer: Macromol. Chem., 82, 175 (1965): 82, 184 (1965).

4) Hui, A. W. and A. E. Hamielec: J. Poly. Sci. Part C, No. 25, 167 (1968).

5) Mizoguchi K., E. O'Shima and H. Inoue: Kagaku Kōgaku, 38, 244 (1974).

6) Takao, M., S. Matsumoto and T. Imoto: Kobunshi Kogaku, 29, 811 (1972).

7) Winslow, F. H. and W. Matreyek: Ind. Eng. Chem., 43, 1108 (1951) 